\title{
Review Article \\ Endocrine-Disrupting Chemicals: Some Actions of POPs on Female Reproduction
}

\author{
Ewa L. Gregoraszczuk and Anna Ptak \\ Department of Physiology and Toxicology of Reproduction, Institute of Zoology, Jagiellonian University, \\ Gronostajowa 9, 30-387 Krakow, Poland
}

Correspondence should be addressed to Ewa L. Gregoraszczuk; ewa.gregoraszczuk@uj.edu.pl

Received 7 January 2013; Accepted 26 April 2013

Academic Editor: Radmila Kovacevic

Copyright (C) 2013 E. L. Gregoraszczuk and A. Ptak. This is an open access article distributed under the Creative Commons Attribution License, which permits unrestricted use, distribution, and reproduction in any medium, provided the original work is properly cited.

\begin{abstract}
Persistent organic pollutants (POPs), such as polychlorinated dibenzo-p-dioxins (PCDDs) and dibenzofurans (PCDFs), polychlorinated biphenyls (PCBs), and polybrominated ethers (PBDEs), chloronaftalens (PCNs), and bisphenol A (BPA), are stable, lipophilic pollutants that affect fertility and cause serious reproductive problems, including ovotoxic action, lack of ovulation, premature ovarian failure (POF), or polycystic ovarian syndrome (PCOS). Most of the representatives of POPs influence the activation of transcription factors, not only activation of aromatic hydrocarbon receptor (AhR), but also the steroid hormone receptors. This minireview will focus on a variety of PAH activities in oocyte, ovary, placenta, and mammary gland. The complexity and diversity of factors belonging to POPs and disorders of the reproductive function of women indicate that the impact of environmental pollution as an important determinant factor in fertility should not be minimize.
\end{abstract}

\section{Introduction}

For the past decade, scientists, institutions, governments, and policymakers have warned the general public about serious health hazards associated with chemicals known as endocrine disruptors (EDs). EDs are exogenous compounds that interfere with the synthesis, secretion, transport, metabolism, and/or action of endogenous hormones that are responsible for normal homeostasis, reproduction, and development. Chemicals with hormonal activity can be divided into three main groups: (i) synthetic compounds used in industry and agriculture as well as in consumer products, (ii) synthetic compounds used in pharmaceutical drugs, and (iii) natural compounds present in the food chain (i.e., phytoestrogens, compounds that are structurally similar to estrogen (E2)). Only (i) synthetic compounds used in industry and agriculture and consumer products will be discussed in presented paper. Within this class, compounds can be further subcategorized into those that are persistent in all elements of the environment, bio-accumulative, transportable over long distances, and capable of adversely affecting life forms that reside within short and long distances from the site of contamination. These compounds include dichlorodiphenyltrichloroethane (DDT, a pesticide), polychlorinated biphenyls (PCBs), polychlorinated naphthalenes (PCNs), polychlorinated dibenzodioxins (PCDDs), polychlorinated dibenzofurans (PCDFs), and polybrominated diphenyl ethers (PBDEs) (Figure 1).

Because xenobiotics can accumulate in the body for an extremely long period of time (i.e., decades), they can be detrimental to human health even at very low doses. For instance, pesticides and other synthetic compounds used in the 1950s have polluted the air that we breathe, the water that we drink, and the soil that we grow our food in. In addition, many of these compounds are nonbiodegradable. Studies have shown the presence of EDS both in adipose tissue and other organs, in almost all humans and many animals. Human exposure to environmental toxicants is mediated via food and water chains, breathing, and dermal absorption, with approximately $90 \%$ of the exposure coming from food. Moreover, several mammalian organs (e.g., ovary, breast, uterus, cervix, bone, muscle, and skin) rely on sex steroids for normal function, and these organs are especially vulnerable to endocrine disruption by environmental toxicants. This 
<smiles>Clc1ccc(C(c2ccc(Cl)cc2)C(Cl)(Cl)Cl)cc1</smiles>

(a)

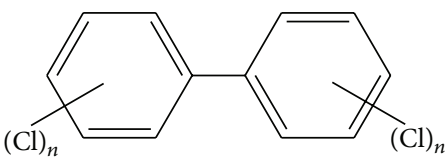

(b)

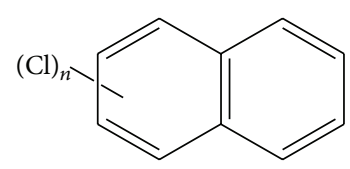

(c)<smiles>Cc1cccc2c1Oc1ccccc1O2</smiles>

(d)<smiles>Clc1ccc2c(c1)oc1c(C(Cl)(Cl)Cl)cccc12</smiles>

(e)<smiles>CC(C)(C)c1cccc(Oc2ccccc2)c1</smiles>

(f)

Figure 1: Generic structure of the (a) DDT, (b) PCBs, (c) PCNs, (d) PCDDs, (e) PCDFs, and (f) PBDEs.

chapter will focus only on selected actions or abnormalities. Much of the information on the impact of EDs on human health has come from in vivo studies where animals were exposed to a single compound, usually at an acute (i.e., pharmacological) dose; however, humans are exposed to several compounds at unknown concentrations for unknown durations. For example, hospital patients receive an average of six drugs daily (i.e., aspirin, antihistamines, antibiotics, anti-cough syrup, etc.). Food and water may also contain low levels of organic and inorganic compounds (e.g., pesticides and heavy metals) and solvents (e.g., benzene, toluene, and chloroform), and air is filled with hundreds of chemicals (e.g., industrial pollutants, smoke, gasoline vapors, etc.). The ability of these environmental toxicants to affect human health depends on several factors, including interactions between compounds; absorption, metabolism, accumulation, and excretion of compounds; and the ability of some compounds bind to cell receptors which can affect hormone action. Unfortunately, little is known about how these environmental toxicants interact with each other existing in a mixture. It is known that such xenobiotic acts in different ways depending on whether their action is observed on the fetus, newborn babies, or adult individuals, depending on the period during whose body has been exposed to these factors. In many cases, the effect of their actions may be undetected until sexual maturity, especially when exposure occurs during a period of embryonic development or shortly after birth. The female reproductive cycle is a complex process comprised of gametogenesis, embryogenesis, menstruation, ovulation, possible pregnancy, endometrial, and mammary gland changes. Development of the female reproductive system during fetal life determines reproductive success. Women are born with all the oocytes they will ever have through their life, and therefore oocytes are more vulnerable to toxic chemicals than germ cells in men who continue to make more germ cells.

\section{Actions on the Oocyte}

Oocyte maturation, the final step of germ cell differentiation, determines reproductive capacity. Follicles are especially susceptible to the adverse effects of environmental toxicants, and developing oocytes may be damaged directly or indirectly by action on follicular cells (i.e., granulosa cells) that may also be vulnerable to endocrine disruption, thereby affecting oocyte function indirectly. A previous study illustrated that human oocytes harvested from follicles with elevated levels of polycyclic aromatic hydrocarbons (PCAHs) had fewer cell divisions after in vitro fertilization [1]. Chloroorganic mixtures such as PCBs and DDT, as well as its metabolites, have also been reported to affect puberty, development, and oocyte viability adversely [2]. Some of these studies point to unpredictable changes of translational regulation within the oocyte under the influence of PCBs [3]. Polyspermia (secretion of an excessive amount of semen) has also been demonstrated in cattle exposed to an environmentally relevant mixture of more than 15 organochlorines [4]. Presently, additional research is needed to better understand the molecular mechanisms behind mammalian ovotoxicity caused by exposure to environmental toxicants.

Ovarian function is controlled by the hypothalamus, pituitary, and autoparacrine factors. Hormone-mimicking compounds can bind to cell receptors, interfere with hormone action, and affect ovarian function. How EDs affect ovarian function is not yet clear, but a disruption in gonadotropin (i.e., follicle stimulating hormone (FSH) and luteinizing hormone $(\mathrm{LH})$ ) secretion and feedback mechanisms involving E2 and progesterone (P4) may be involved. Alternatively, EDs may affect ovarian hormone production and oocyte maturation. Damaged oocytes can affect overall hormone production and follicular function, resulting in an endocrinological imbalance (i.e., a decrease in E2 and P4, but an increase in FSH and $\mathrm{LH}$ ) and ovarian failure.

\section{Actions on the Ovary}

3.1. Disruption of Ovarian Function. Fertility in sexually mature women depends largely on the maintenance of healthy follicles, and their steady production ensures that 
an adequate number of follicles reach the antral stage. The stage of development at which the follicles are destroyed determines the influence of these factors on the fertility of women. Complete depletion of the follicle reserve results in irreversible infertility; partial depletion of the follicle reserve results in moderate effects on periodicity. Damage to large follicles can also lead to reversible acyclic disorders that affect hormone production and ovulation. Nevertheless, the effects of POPs on the hypothalamic-pituitary-ovarian (HPO) axis are generally reversible because they do not permanently affect the follicle reserve.

3.1.1. TCDD. TCDD (2, 3, 7, 8-teterachlorodibenzo-paradioxin) is an isomer of PCDD, and one of the most toxic man-made compounds to pollute our environment. Studies on the mechanism of TCDD action during ovulation indicate a dysfunction in the HPO axis. Misregulation of FSH and LH secretion before ovulation was noted in rats exposed to TCDD. Moreover, gonadotropin-releasing hormone ( $\mathrm{GnRH}$ ) inhibited the surge in FSH and LH secretion, thereby restoring ovulation $[5,6]$. TCDD also inhibited FSH secretion and downregulated FSH receptor gene expression [7]. TCDD affected the levels of other hormones as well. For instance, Gore [8] showed methoxychlor to affect GnRH expression in hypothalamic GT1-7 cells. In a study from our laboratory, TCDD inhibited E2 secretion by follicular cells and P4 secretion by luteal cells dose-dependently. These adverse effects on hormone production were mediated in part by enzymes involved in steroidogenic biosynthesis. In luteal cells, TCDD action was independent of E2 receptor stimulation, instead involving the aryl hydrocarbon receptor (AhR) [9]. On a final note, other environmental toxicants (i.e., PCDFs, biphenyls, DDT, and methoxychlor) can also block the surge in LH and FSH secretion during the female reproductive cycle $[10,11]$.

3.1.2. PCBs. Polychlorinated biphenyls (PCBs) are the manmade chemicals that may disrupt follicular steroidogenesis either by mimicking natural hormones as agonist or antagonist, altering the pattern of hormone synthesis, modulating hormone receptor affinities or numbers, or by altering enzymes involved in hormone secretion. In our previous study, we showed that the orthosubstituted PCB 153 congener accumulated preferentially in the follicular wall when compared to the nonorthosubstituted PCB 126 congener. 71\%, $71.4 \%$, and $30.4 \%$ of the total exposure for PCB 153 were in small, medium, and large follicles, respectively (Figure 1). Interestingly, about $70 \%$ of PCB153 accumulated in early antral and antral follicles and only $30 \%$ in preovultory follicles. The consequence was a reduction in estradiol secretion by early antral and antral follicles and lack of influence on estradiol secretion by preovulatory follicles. Moreover, Moreover, it has been showed that action on estradiol secretion was correlated with action on aromatase activity [12-14]. A similar dose-responsive relationship was reported after exposure of follicular cells to a mixture of organic pollutants [15] or a mixture of PBDEs [16].

3.1.3. PBDEs. Polybrominated dibenzoethers (PBDEs) are persistent and ubiquitous environmental toxicants found at increasing levels in humans and animals. Despite recent bans by the European Union [17], United States, and China on the production of penta- and octa-BDE as well as on the diminished use of PBDE in Japan [18], 2,2',4,4' -tetra-BDE

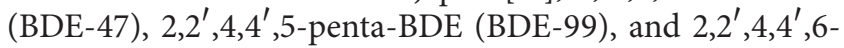
penta-BDE (BDE-100) are the major PBDE congeners present in humans and animals [19]. The literary data related to the effects of PBDE mixture are limited predominantly to commercial mixture DE-71 which contains mainly penta-BDEs (BDE-99 and BDE-100) and tetra-BDE (BDE-47). Zhou et al. [20] and Stoker et al. [21] indicated that DE-71 (a mixture of BDE-99, BDE-100, and tetra-BDE) affected the production of thyroid and sex steroids and the development of reproductive organs [20, 21]. Results from our laboratory have shown an increase in the $\mathrm{P} 4 /$ testosterone $(\mathrm{T})$ ratio but a decrease in the T/E2 ratio, in ovarian follicles suggesting premature luteinization of antral follicles. Removal of the PBDE mixture from cell cultures did not reverse adverse effects [22]. In a follow-up study, we reported changes in the levels of steroidogenic enzymes (e.g., $17 \beta$-hydroxysteroid dehydrogenase (17 $\beta$ HSD), cytochrome P450, family 17, subfamily A, polypeptide 1 (CYP17), and aromatase (CYP19)) by PBDE congeners 47, 99, and 100 [23]. Last published data showed fast activation of CYP2B1/2, and late activation of COMT (with a very low basal SULT1A activity) in ovarian follicles by BDE-47 indicates a possible action of locally produced hydroxylated metabolites prior to their detoxification [24]. Additionally, it have been showed that 5-OH-BDE-47 and 6-OH-BDE-47 have a different mechanism of action in ovarian follicles from their parent compound and lead to an increase in estradiol secretion. The metabolites stimulate aromatase expression and activity, while the parent compound increases androgen production and stimulation of $17 \beta$-HSD protein expression and activity [25].

3.1.4. PCNs. Polychlorinated naphthalenes (PCNs) are members of a large and diverse group of compounds with several industrial applications. PCNs occur as mixtures of congeners sold under various trade names (e.g., Halowax, Nibren Wax, and Seekay Wax) [26]. The toxicological characteristics of PCNs are similar to those caused by PCBs, PCDDs, and PCDFs $[27,28]$. Presently, there are little data on the toxicity of PCNs in experimental animals, and our recently published data was the first showed direct action on ovarian function. We showed an increase in basal testosterone secretion in all doses used, with the highest stimulatory action of the smallest dose, which was accompanied by a parallel decrease in basal estradiol secretion, induced by Halowax 1051 suggesting androgenic properties of Halowax 1051. As a mechanism we propose direct stimulatory action on $17 \beta$-HSD activity and protein expression, enzyme responsible for testosterone synthesis and inhibitory action on CYP19 activity, and enzyme responsible for conversion testosterone to estradiol [29]. It should be taken into consideration that as in the case of BDE47 [24], the effects of exposure to PCNs may be due to the side effects of PCN metabolites. Examining the effects of the Halowax 1051 on phase I (CYP1A1) and phase II (SULT1A and COMT) enzyme activities and expression in cultured ovarian follicles we showed fast activation of enzymes involved in 
phase I and concurrent inhibition of enzymes involved in phase II metabolism confirming our suggestion that the observed effects of Halowax 1051 are partially result from the action of metabolites formed locally in ovarian follicles [30].

3.1.5. HCBz. Data on the effects of hexachlorobenzene $(\mathrm{HCBz})$ on reproduction are scant. While $\mathrm{HCBz}$ is toxic to humans [31, 32] and animals [33], information on the effects of $\mathrm{HCBz}$ in ovarian steroidogenesis is limited despite data that showed an increase in the P4 serum level in superovulated rats exposed to $\mathrm{HCBz}$ [34]. Treatment of Cynomolgus monkeys with $\mathrm{HCBz}$, on the other hand, decreased the $\mathrm{P} 4$ serum level and unaltered the E2 serum level during the luteal phase. In a recently published study, we determined in vitro accumulation of hexachlorobenzene $(\mathrm{HCBz})$ and pentachlorobenzene $(\mathrm{PeCBz})$ in porcine ovarian follicles, the effect on steroidogenesis, and the expression of enzymes responsible for steroid synthesis [35]. We showed that sixty percent of the $\mathrm{HCBz}$ and almost $100 \%$ of the $\mathrm{PeCBz}$ that was added to the culture medium accumulated in ovarian tissue, and only $1 \%$ of each was found in the medium. Moreover, we showed inhibitory $\mathrm{HCBz}$ effect and stimulatory $\mathrm{PeCBz}$ effect on testosterone and estradiol secretion. As a conclusion we mentioned that the greater exposure to an estrogenic action of $\mathrm{PeCBz}$ than antiestrogenic $\mathrm{HCBz}$ would be a consequence of the preferential accumulation of $\mathrm{PeCBz}$ in the ovarian follicles. Another situation was observed in human placental tissue. Both $\mathrm{HCBz}$ and $\mathrm{PeCBz}$ did not accumulate in placental tissue. We showed that $\mathrm{HCBz}$ by fast activation of I and II phase metabolism is probably metabolized to $\mathrm{PeCBz}$ in placental tissue (Gregoraszczuk et al., unpublished data).

3.1.6. A Mixture of Environmental Toxicants. Toxicants usually occur in a mixture of several toxicants, making it difficult to predict adverse effects on human health. Younglai et al. [36] demonstrated human follicular fluid obtained from women to contain 1, 1-dichloro-2, 2-bis (p-chlorophenyl)-ethylene ( $\mathrm{p}, \mathrm{p}^{\prime}$-DDE), mirex (a pesticide), hexachloro-ethane 1, 2, 4trichlorobenzene, and numerous PCBs (i.e., PCBs 49, 153, and 180). Of these, $\mathrm{p}, \mathrm{p}^{\prime}$-DDE was the most frequently detected $\mathrm{ED}$ in follicular fluid and serum. Several environmental toxicants are ER agonists, and they include estrogenic steroids (natural and synthetic), phyto- and mycoestrogens, and xenoestrogens (e.g., pesticides, plasticizers, and alkylphenols). In addition to simple additive effects [37], interactions between different chemicals in a mixture may result in either a weaker (antagonistic) [38] or stronger (synergistic, potentiated) combined effect than would be expected from knowledge about the toxicity and mode of action of each individual compound. These interactions may occur during toxicant uptake, distribution, metabolism, and/or excretion (i.e., toxicokinetic phase), or during toxicant binding to receptors and cellular targets (i.e., toxicodynamic phase) $[39,40]$. A mixture of xenoestrogens may alter the way a cell responds to endogenous estrogens. For instance, xenoantiestrogens found within mixtures can inhibit endogenous E2. Moreover, some estrogenic compounds exert their effects, not by binding to ER but rather by binding to estrogen plasma transport proteins, resulting in an increase in free endogenous E2.
Nevertheless, mixtures containing both xenoestrogens and endoantiestrogens may have no adverse effects [41]. In our previously published data, to determine which compounds within a PCB-DDT-DDE mixture stimulated E2 secretion, we exposed cells to PCBs 118, 138, 153, and 180, DDT, and DDE alone or in different combinations. Interestingly, DDT and DDE affected E2 secretion [42], and these results are in agreement with another series of experiments that used mixtures of PBDEs [43]. In the next experiments, using Western blot analysis indicated that PCBs mixture ("Marine mix") is an inducer of AhR and mixed-type CYP inducer (CYP1A1 and CYP2B1) while PBDEs mixture ("Mjosa mix") is an inducer of $\mathrm{ER} \beta$ and CYP2B [44].

\subsection{Pathology of the Ovary}

3.2.1. Early Puberty. Early puberty is a recent growing concern as there are reports of many girls reaching their first menstruation and developing breasts earlier in life than was the case 40 years ago [45]. Early puberty associates with polycystic ovarian syndrome (PCOS), obesity, breast cancer, depression, and a number of social challenges such as experimentation with sex, alcohol, or drugs at a younger age. Moreover, earlier menarche and thelarche ages have been reported in girls after exposure to PCBs, PBBs, DDT, and/or phthalate esters $[46,47]$, and precocious puberty has been observed following exposure to DDT metabolites [48].

3.2.2. Polycystic Ovarian Syndrome (PCOS). The acyclicity of the syndrome is linked with the hyperfunctioning of theca and hypofunctioning of granulosa cells. PCOS also associates with other processes (e.g., neuroendocrine function and ovarian steroidogenesis) and diseases (e.g., insulin resistance, and obesity) that are regulated by hormonal and metabolic factors. Thus, exposure to environmental toxicants may indeed contribute to the pathogenesis of PCOS. For instance, women with PCOS have higher levels of bisphenol A (BPA, a plastics additive) [49] and testosterone which is consistent with the decreased clearance of BPA that is often observed [50]. Although a cause-and-effect relationship has not been established, the role of environmental toxicants in the pathogenesis of PCOS is worthy of further consideration.

3.2.3. Premature Ovarian Failure (POF). POF, the cessation of normal ovarian function before the age of 40 , occurs in approximately $1 \%$ of women of reproductive age [51]. The underlying causes of POF are largely known in most cases, and any factor that can decrease the ovarian reserve can result in POF. For instance, disruption of germ cell migration from the genital ridge to the developing gonad results in ovarian dysgenesis and POF. In addition, adult and in utero exposure of mice to BPA resulted in oocyte damage $[52,53]$, whereas exposure of women to cigarette smoke decreased fertility, in vitro fertilization (IVF) success rates, and the ovarian reserve resulted in earlier menopause and increased miscarriage rate [54]. In another study, exposure of rats to TCDD in utero and throughout reproductive life resulted in premature reproductive senescence [55]. Endocrine disruption caused by acute exposure to environmental toxicants such as the 
AhR agonist TCDD suggests that AhR-mediated apoptosis of oocytes may be involved.

\section{Hormone-Dependent Cancer}

4.1. Breast Cancer. Breast cancer is the most frequent neoplasm affecting women residing in Western countries and is the second leading cause of death [56]. The general population is exposed to several hormonally active compounds on a daily basis. The majority of these compounds are xenoestrogens (e.g., PCAHs, pesticides, PCBs, PBDEs, DDT, selected drugs, fungicides, phytoestrogens, mycotoxins, BPA, and phthalates), and they can possess estrogenic action, affect estrogen levels, and/or bind to ERs [57].

4.1.1. Recent Findings on PCBs. The role of PCBs in breast cancer has been investigated intensively. Data suggest that a correlation may exist between high levels of PCBs in mammary tissues or sera and breast cancer risk [58], while another study reported no association [59]. High PCB levels upregulated CYP expression [60], suggesting that PCB metabolites may be critical for the pathogenesis of breast cancer. Likewise, Pang and colleagues [61] reported that exposure of MCF-7 human breast cancer cells to PCBs 81, 126, and 39 increased CYP1A1 and CYP1B1 mRNA levels, resulting in the formation of E2 metabolites. We demonstrated PCB 3 to induce and to be a substrate for CYP1Alin MCF-7 cells [62]. On the other hand, others have shown PCBs 52 and 77 to induce oxidative damage (i.e., DNA strand breaks) in ER $\alpha(-) / \mathrm{MDA}$ breast cancer cells but not in ER $\alpha(+)$ /MCF-7 cells [63], suggesting that the $\mathrm{ER} \alpha$ receptor may play a protective role in breast cancer. Moreover, PCBs can interfere with the balance between proliferation and apoptosis. Radice et al. [64] demonstrated those PCB congeners such as PCBs 101, 118, 138, 153, and 180 increased proliferations of MCF-7 cells. Our published data demonstrated that from investigated congeners $(118,138$, 153, and 180), PCB138 and 153 had the highest stimulatory effects on basal MCF-7 cell proliferation as well as the highest inhibitory actions on basal caspase-9 activity. Moreover, we showed that PCBs 138 and 153 contribute to the action of endogenous $17 \beta$-estradiol on cell proliferation and apoptosis in the breast cancer cell line MCF-7 [65]. In vivo experiments have also shown PCBs to increase metastasis by triggering the production of reactive oxygen species (ROS), thereby activating the Rho-associated protein kinase (ROCK) signaling pathway [66] or vascular endothelial growth factor (VEGF) overexpression that stimulates endothelial hyperpermeability and transendothelial migration of cancer cells [67].

4.1.2. Recent Findings on PBDEs. Data on the effects of PBDEs on breast cancer are scant. PBDEs trigger micronucleus formation and proliferation in MCF-7 cells [68]. An increase in MCF-7 cell proliferation by DE-71 (a mixture of BDE$47,-99,-100,-153$, and -154) was also reported by MercadoFeliciano and Bigsby [69]. PBDE-209 also induced MCF-7 cell proliferation by affecting critical steps of the cell cycle [70]. At the molecular level, PBDE-209 triggered protein kinase $\mathrm{C} \alpha(\mathrm{PKC} \alpha)$ and ERK1/2 phosphorylation. On the other hand, Kwiecińska et al. [71] have shown no changes in
MCF-7 cell proliferation following exposure to BDE-47, -99, 100 , and -209 ; however, apoptosis was inhibited by decreasing caspase-9 activity in these cells [71]. Resistance to apoptosis associates with tumorigenesis as it enables tumorigenic cells to expand even in a stressful environment. Thus, additional studies are needed to determine if exposure to PBDEs can indeed cause breast cancer.

4.1.3. Recent Findings on Bisphenol A (BPA). Laboratory studies in rodents suggest a link between BPA exposure and breast cancer incidence. When rodents were exposed to BPA early in life, there were changes in mammary gland morphogenesis and tumor susceptibility [72-74]. These findings are supported by in vitro data which demonstrated BPA to induce transformation of MCF-10F human breast cancer cells. These cells formed tubule-like structures when cultured in 3D collagen matrix, but spherical masses were noted after BPA treatment [75], leading the authors to conclude that BPA produces adducts or ROS which can inadvertently introduce a variety of DNA modifications and cause breast cancer. Others have shown BPA to stimulate proliferation but to inhibit apoptosis in MCF-7 cells [76-78]. BPA may also induce breast cancer cell proliferation by upregulating cell cycle genes and downregulating antiproliferative genes, especially genes that control the G1/S transition via ER $\alpha$ signaling [79].

4.2. Ovarian Cancer. Ovarian cancer is the most prevalent type of gynecological cancer affecting women residing in Western countries. As more than $60 \%$ of tumors are diagnosed at stage III and certain forms of cancer are very aggressive, ovarian cancers are associated with a high mortality. While most cells undergo neoplastic transformation, including germ cells, granulose, and stromal cells, approximately $90 \%$ of tumors are derived from the ovarian surface epithelium (OSE). Similar to breast cancer, hormonal factors such as estrogen and xenoestrogens have been linked to ovarian cancer [80,81]; however, the role of environmental toxicants in ovarian cancer requires further study.

4.2.1. Recent Findings on PCBs and PBDEs. The role of PCBs in the initiation and progression of ovarian cancer is unknown. Studies in adult C57BL mice showed that orally administered PBDEs-47, -85 , and -99 to accumulate in the liver, adrenal cortex, and ovary in adult C57BL mice [82] suggest a possible carcinogenic activity, especially in light of research showing that exposure of $\mathrm{CHO}$ and OVCAR-3 cells to PBDE-209 initiated S and G2/M phases of the cell cycle, respectively [83].

4.2.2. Recent Findings on BPA. Several in vitro studies have shown BPA to induce chromosomal aberrations in $\mathrm{CHO}$ cells $[84,85]$, a common genetic alteration in cancer. Moreover, ovarian cyst formation was observed in mice treated neonatally with BPA [86]. Ovarian cancer may stem from incessant ovulation, which may be linked to the formation of cysts that are frequently found in perimenopausal women. In a study from our laboratory, we demonstrated an increase in proliferation in OVCAR- 3 cells treated with BPA. Specifically, we showed BPA to promote the cell cycle by upregulating 
the expression of cyclin D1, CDK4, E2F1, E2F3, and PCNA (a mediator of G1 to S-phase progression) and cyclin A (a mediator of G2-phase progression to mitosis), but by downregulating the expression of p21WAF1/CIP1, Weel-1, and GADD $45 \alpha$ [87]. Additionally, we demonstrated a decrease in the expression of proapoptotic genes (i.e., FAS, FADD, RAIDD, caspase- $8,-10,-3,-6$, and 7, CAD, Bax, Bak, Bok, and Apaf-1) but an increase in the expression of prosurvival genes (i.e., Bcl-x and Mcl-1). BPA also activates a caspasesindependent apoptotic pathway by inducing endonuclease $\mathrm{G}$ gene expression. Also, Hwang et al. [88] using microarray analysis increased mRNA levels of E2-responsive genes in ER-positive ovarian cancer BG-1 cells under the influence of BPA. In a subsequent study, we showed BPA to trigger phosphorylation of Stat3, ERK1/2, and Akt in OVCAR-3 cells [89]. Cited results of research indicated that BPA acting as a mitogen as well as an antiapoptotic factor may be an additional factor responsible for ovarian cancer.

\section{Conclusions}

In recent years there has been a growing evidence that exposure to chemicals in the environment poses a serious threat to human and animals reproduction via disrupting effects on endocrine function. Despite the fact that these substances are persistent, they may be metabolized into more toxic compounds than the parent molecule in endocrine organs. This endocrine disrupting chemicals (EDCs) adversely affect health and reproduction even at very low concentrations and may exert their effects on the embryo and fetus. The complexity and diversity of factors belonging to EDCs, its direct action on the ovary, and disorders of the reproductive function of women indicate that the impact of environmental pollution as an important determinant factor in fertility should not be minimize. Current estimates of cancer risk in humans do not account properly for transplacental and environmental (including occupational) exposure to xenoestrogens. It is important to reevaluate the role of xenoestrogens in cancer development using new approaches that better reflect the complexity of carcinogenesis. Testing new compounds before they are allowed to use should be expanded to determine their effect on the endocrine system, in order to assess the hormonal activity. In addition, attention should be directed towards dose-response relationships in environmental toxicology. Such studies can provide useful information that might have a significant impact on the strategies for risk assessment of toxic substances.

\section{Acknowledgment}

This research is supported by K/ZDS/002592 Jagiellonian University in Cracow, Poland.

\section{References}

[1] P. Pocar, T. A. L. Brevini, B. Fischer, and F. Gandolfi, "The impact of endocrine disruptors on oocyte competence," Reproduction, vol. 125 , no. 3, pp. 313-325, 2003.

[2] C. Campagna, M. A. Sirard, P. Ayotte, and J. L. Bailey, "Impaired maturation, fertilization, and embryonic development of porcine oocytes following exposure to an environmentally relevant organochlorine mixture," Biology of Reproduction, vol. 65, no. 2, pp. 554-560, 2001.

[3] P. Pocar, T. A. L. Brevini, F. Perazzoli, F. Cillo, S. Modina, and F. Gandolfi, "Cellular and molecular mechanisms mediating the effects of polychlorinated biphenyls on oocyte developmental competence in Cattle," Molecular Reproduction and Development, vol. 60, no. 4, pp. 535-541, 2001.

[4] C. Campagna, C. Guillemette, R. Paradis, M. A. Sirard, P. Ayotte, and J. L. Bailey, "An environmentally relevant organochlorine mixture impairs sperm function and embryo development in the porcine model," Biology of Reproduction, vol. 67, no. 1, pp. 80-87, 2002.

[5] B. Eskenazi, M. Warner, P. Mocarelli et al., "Serum dioxin concentrations and menstrual cycle characteristics," American Journal of Epidemiology, vol. 156, no. 4, pp. 383-392, 2002.

[6] X. Gao, B. K. Petroff, K. K. Rozman, and P. F. Terranova, "Gonadotropin-releasing hormone $(\mathrm{GnRH})$ partially reverses the inhibitory effect of 2,3,7,8-tetrachlorodibenzo-p-dioxin on ovulation in the immature gonadotropin-treated rat," Toxicology, vol. 147, no. 1, pp. 15-22, 2000.

[7] T. Hirakawa, T. Minegishi, K. Abe et al., "Effect of 2,3,7,8tetrachlorodibenzo-p-dioxin on the expression of folliclestimulating hormone receptors during cell differentiation in cultured granulosa cells," Endocrinology, vol. 141, no. 4, pp. 1470-1476, 2000.

[8] A. C. Gore, "Organochlorine pesticides directly regulate gonadotropin-releasing hormone gene expression and biosynthesis in the GT1-7 hypothalamic cell line," Molecular and Cellular Endocrinology, vol. 192, no. 1-2, pp. 157-170, 2002.

[9] E. L. Gregoraszczuk, E. Zabielny, and D. Ochwat, "Aryl hydrocarbon receptor (AhR)-linked inhibition of luteal cell progesterone secretion in 2,3,7,8-tetrachlorodibenzo-p-dioxin treated cells," Journal of Physiology and Pharmacology, vol. 52, no. 2, pp. 303-311, 2001.

[10] X. Gao, P. F. Terranova, and K. K. Rozman, "Effects of polychlorinated dibenzofurans, biphenyls, and their mixture with dibenzo-p-dioxins on ovulation in the gonadotropin-primed immature rat: support for the toxic equivalency concept," Toxicology and Applied Pharmacology, vol. 163, no. 2, pp. 115$124,2000$.

[11] K. Okazaki, S. Okazaki, S. Nishimura et al., "A repeated 28-day oral dose toxicity study of methoxychlor in rats, based on the "enhanced OECD test guideline 407" for screening endocrinedisrupting chemicals," Archives of Toxicology, vol. 75, no. 9, pp. 513-521, 2001.

[12] E. L. Gregoraszczuk, A. Grochowalski, R. Chrzaszcz, and M. Wegiel, "Congener-specific accumulation of polychlorinated biphenyls in ovarian follicular wall follows repeated exposure to PCB 126 and PCB 153. Comparison of tissue levels of PCB and biological changes," Chemosphere, vol. 50, no. 4, pp. 481488, 2003.

[13] A. K. Wojtowicz, E. Ropstad, and E. L. Gregoraszczuk, "Estrous cycle-dependent changes in steroid secretion by pig ovarian cells exposed in vitro to polychlorinated biphenyl (PCB 153)," Endocrine Regulations, vol. 35, no. 4, pp. 223-228, 2001.

[14] E. L. Gregoraszczuk, M. Sowa, M. Kajta, A. Ptak, and A. Wójtowicz, "Effect of PCB 126 and PCB 153 on incidence of apoptosis in cultured theca and granulosa cells collected from small, medium and large preovulatory follicles," Reproductive Toxicology, vol. 17, no. 4, pp. 465-471, 2003. 
[15] E. L. Gregoraszczuk, K. Milczarek, A. K. Wójtowicz, V. Berg, J. U. Skaare, and E. Ropstad, "Steroid secretion following exposure of ovarian follicular cells to three different natural mixtures of persistent organic pollutants (POPs)," Reproductive Toxicology, vol. 25, no. 1, pp. 58-66, 2008.

[16] BSEF, "Bromine science and enviromental forum," 2007, http:// www.bsef.com/.

[17] K. Akutsu and S. Hori, "Polybrominated diphenyl ether flame retardants in foodstuffs and human milk," Shokuhin Eiseigaku Zasshi, vol. 45, no. 4, pp. 175-183, 2004.

[18] I. A. T. M. Meerts, R. J. Letcher, S. Hoving et al., "In vitro estrogenicity of polybrominated diphenyl ethers, hydroxylated PBDEs, and polybrominated bisphenol A compounds," Environmental Health Perspectives, vol. 109, no. 4, pp. 399-407, 2001.

[19] A. Sjodin, D. G. Patterson Jr., and A. Bergman, "A review on human exposure to brominated flame retardants-particularly polybrominated diphenyl ethers," Environment International, vol. 29, no. 6, pp. 829-839, 2003.

[20] T. Zhou, M. M. Taylor, M. J. De Vito, and K. M. Crofton, "Developmental exposure to brominated diphenyl ethers results in thyroid hormone disruption," Toxicological Sciences, vol. 66, no. 1, pp. 105-116, 2002.

[21] T. E. Stoker, S. C. Laws, K. M. Crofton, J. M. Hedge, J. M. Ferrell, and R. L. Cooper, "Assessment of DE-71, a commercial polybrominated diphenyl ether (PBDE) mixture, in the EDSP male and female pubertal protocols," Toxicological Sciences, vol. 78, no. 1, pp. 144-155, 2004.

[22] A. Karpeta and E. L. Gregoraszczuk, "Mixture of dominant PBDE congeners (BDE-47, -99, -100 and -209) at levels noted in human blood dramatically enhances progesterone secretion by ovarian follicles," Endocrine Regulations, vol. 44, no. 2, pp. 49-55, 2010.

[23] A. Karpeta, A. Rak-Mardyła, J. Jerzak, and E. L. Gregoraszczuk, "Congener-specific action of PBDEs on steroid secretion, CYP17, 17 $\beta$-HSD and CYP19 activity and protein expression in porcine ovarian follicles," Toxicology Letters, vol. 206, pp. 258263, 2011.

[24] A. Karpeta, K. Warzecha, J. Jerzak, A. Ptak, and E. L. Gregoraszczuk, "Activation of the enzymes of phase I, (CYP2B1/2) and phase II, (SULT1A and COMT) metabolism by $2,2^{\prime}, 4,4^{\prime}$ tetrabromodiphenyl ether (BDE47) in the pig ovary," Reproductive Toxicology, vol. 34, pp. 436-442, 2012.

[25] A. Karpeta, J. Barc, and A. Ptak, "Gregoraszczuk EL. The 2, 2', 4, $4^{\prime}$-tetrabromodiphenyl ether hydroxylated metabolites 5-OHBDE-47 and 6-OH-BDE-47 stimulate estradiol secretion in the ovary by activating aromatase expression," Toxicology, vol. 305, pp. 65-70, 2013.

[26] J. Falandysz, "Chloronaphthalenes as food-chain contaminants: a review," Food Additives and Contaminants, vol. 21, pp. 9951014, 2003.

[27] A. L. Blankenship, K. Kannan, S. A. Villalobos et al., "Relative potencies of individual polychlorinated naphthalenes and halowax mixtures to induce Ah receptor-mediated responses," Environmental Science and Technology, vol. 34, no. 15, pp. 31533158, 2000.

[28] D. L. Villeneuve, K. Kannan, J. S. Khim et al., "Relative potencies of individual polychlorinated naphthalenes to induce dioxinlike responses in fish and mammalian in vitro bioassays," Archives of Environmental Contamination and Toxicology, vol. 39, no. 3, pp. 273-281, 2000.

[29] E. Ł. Gregoraszczuk, J. Jerzak, A. Rak-Mardyła, and J. Falandysz, "Halowax 1051 affects steroidogenesis, 17 $\beta$-hydroxysteroid dehydrogenase (17 $\beta$-HSD) and cytochrome P450arom (CYP19) activity, and protein expression in porcine ovarian follicles," Reproductive Toxicology, vol. 32, pp. 379-384, 2011.

[30] J. Barc, A. Karpeta, and E. L. Gregoraszczuk, "Action of halowax 1051 on enzymes of phase I, (CYP1A1) and phase II, (SULT1A and COMT) metabolism in the pig ovary," International Journal of Endocrinology, vol. 2013, Article ID 590261, 7 pages, 2013.

[31] J. F. Jarrell, A. Gocmen, D. Akyol, and R. Brant, "Hexachlorobenzene exposure and the proportion of male births in Turkey 1935-1990," Reproductive Toxicology, vol. 16, no. 1, pp. 65-70, 2002.

[32] N. Khanjani and M. R. Sim, "Reproductive outcomes of maternal contamination with cyclodiene insecticides, hexachlorobenzene and $\beta$-benzene hexachloride," Science of the Total Environment, vol. 368, no. 2-3, pp. 557-564, 2006.

[33] L. Alvarez, A. Randi, P. Alvarez et al., "Reproductive effects of hexachlorobenzene in female rats," Journal of Applied Toxicology, vol. 20, pp. 81-87, 2000.

[34] W. G. Foster, J. A. Pentick, A. McMahon, and P. R. Lecavalier, "Ovarian toxicity of hexachlorobenzene (HCB) in the superovulated female rat," Journal of Biochemical Toxicology, vol. 7, no. 1, pp. 1-4, 1992.

[35] E. Ł. Gregoraszczuk, A. Ptak, A. Rak-Mardyła, and J. Falandysz, "Differential accumulation of $\mathrm{HCBz}$ and $\mathrm{PeCBz}$ in porcine ovarian follicles and their opposing actions on steroid secretion and CYP11, CYP17, 17 $\beta$-HSD and CYP19 protein expression. A tissue culture approach," Reproductive Toxicology, vol. 31, no. 4, pp. 494-499, 2011.

[36] E. V. Younglai, W. G. Foster, E. G. Hughes, K. Trim, and J. F. Jarrell, "Levels of environmental contaminants in human follicular fluid, serum, and seminal plasma of couples undergoing in vitro fertilization," Archives of Environmental Contamination and Toxicology, vol. 43, no. 1, pp. 121-126, 2002.

[37] K. Ramamoorthy, C. Vyhlidal, F. Wang et al., "Additive estrogenic activities of a binary mixture of $2^{\prime}, 4^{\prime}, 6^{\prime}$-Trichloro- and $2^{\prime}, 3^{\prime}, 4^{\prime}, 5^{\prime}$-tetrachloro-4-biphenylol," Toxicology and Applied Pharmacology, vol. 147, no. 1, pp. 93-100, 1997.

[38] K. C. Donnelly, L. D. Claxton, H. J. Huebner, and J. L. Capizzi, "Mutagenic interactions of model chemical mixtures," Chemosphere, vol. 37, no. 7, pp. 1253-1261, 1998.

[39] S. A. Andric, T. S. Kostic, S. S. Stojilkovic, and R. Z. Kovacevic, "Inhibition of rat testicular androgenesis by a polychlorinated biphenyl mixture Aroclor 1248," Biology of Reproduction, vol. 62, no. 6, pp. 1882-1888, 2000.

[40] E. J. Calabrese and L. A. Baldwin, "Hormesis: U-shaped dose responses and their centrality in toxicology," Trends in Pharmacological Sciences, vol. 22, no. 6, pp. 285-291, 2001.

[41] D. O. Carpenter, K. Arcaro, and D. C. Spink, "Understanding the human health effects of chemical mixtures," Environmental Health Perspectives, vol. 110, no. 1, pp. 25-42, 2002.

[42] E. L. Gregoraszczuk, A. Ptak, M. Karniewska, and E. Ropstad, "Action of defined mixtures of PCBs, p, p'-DDT and its metabolite $\mathrm{p}, \mathrm{p} /$-DDE, on co-culture of porcine theca and granulosa cells: steroid secretion, cell proliferation and apoptosis," Reproductive Toxicology, vol. 26, no. 2, pp. 170-174, 2008.

[43] E. Ł. Gregoraszczuk, A. Rak, K. Kawalec, and E. Ropstad, "Steroid secretion following exposure of ovarian follicular cells to single congeners and defined mixture of polybrominateddibenzoethers (PBDEs), p, $\mathrm{p}^{\prime}$-DDT and its metabolite $\mathrm{p}, \mathrm{p}^{\prime}$ DDE," Toxicology Letters, vol. 178, no. 2, pp. 103-109, 2008.

[44] E. L. Gregoraszczuk, A. Ptak, J. U. Skaare et al., "Mechanisms of action of two different natural mixtures of persistent organic 
pollutants (POPs) in ovarian follicles," Xenobiotica, vol. 39, no. 1, pp. 80-89, 2009.

[45] E. Diamanti-Kandarakis, J. P. Bourguignon, L. C. Giudice et al., "Endocrine-disrupting chemicals: an endocrine society scientific statement," Endocrine Reviews, vol. 30, no. 4, pp. 293-342, 2009.

[46] E. Den Hond, G. Schoeters, W. G. Sippell et al., "Endocrine disrupters and human puberty," International Journal of Andrology, vol. 29, no. 1, pp. 264-271, 2006.

[47] I. Colón, D. Caro, C. J. Bourdony, and O. Rosario, "Identification of phthalate esters in the serum of young Puerto Rican girls with premature breast development," Environmental Health Perspectives, vol. 108, no. 9, pp. 895-900, 2000.

[48] M. Krstevska-Konstantinova, C. Charlier, M. Craen et al., "Sexual precocity after immigration from developing countries to Belgium: evidence of previous exposure to organochlorine pesticides," Human Reproduction, vol. 16, no. 5, pp. 1020-1026, 2001.

[49] T. Takeuchi, O. Tsutsumi, Y. Ikezuki, Y. Takai, and Y. Taketani, "Positive relationship between androgen and the endocrine disruptor, bisphenol A, in normal women and women with ovarian dysfunction," Endocrine Journal, vol. 51, no. 2, pp. 165169,2004

[50] T. Takeuchi, O. Tsutsumi, Y. Ikezuki et al., "Elevated serum bisphenol A levels under hyperandrogenic conditions may be caused by decreased UDP-glucuronosyltransferase activity," Endocrine Journal, vol. 53, no. 4, pp. 485-491, 2006.

[51] P. Sinha and N. Kuruba, "Premature ovarian failure," Journal of Obstetrics and Gynaecology, vol. 27, no. 1, pp. 16-19, 2007.

[52] P. A. Hunt, K. E. Koehler, M. Susiarjo et al., "Bisphenol a exposure causes meiotic aneuploidy in the female mouse," Current Biology, vol. 13, no. 7, pp. 546-553, 2003.

[53] M. Susiarjo, T. J. Hassold, E. Freeman, and P. A. Hunt, "Bisphenol A exposure in utero disrupts early oogenesis in the mouse," PLoS Genetics, vol. 3, no. 1, article e5, 2007.

[54] S. J. Genuis, "Health issues and the environment-an emerging paradigm for providers of obstetrical and gynaecological health care," Human Reproduction, vol. 21, pp. 2201-2208, 2006.

[55] Z. Shi, K. E. Valdez, A. Y. Ting, A. Franczak, S. L. Gum, and B. K. Petroff, "Ovarian endocrine disruption underlies premature reproductive senescence following environmentally relevant chronic exposure to the aryl hydrocarbon receptor agonist 2,3,7,8-tetrachlorodibenzo-p-dioxin," Biology of Reproduction, vol. 76, no. 2, pp. 198-202, 2007.

[56] J. V. Lacey Jr., S. S. Devesa, and L. A. Brinton, "Recent trends in breast cancer incidence and mortality," Environmental and Molecular Mutagenesis, vol. 39, no. 2-3, pp. 82-88, 2002.

[57] I. A. T. M. Meerts, R. J. Letcher, S. Hoving et al., "In vitro estrogenicity of polybrominated diphenyl ethers, hydroxylated PBDEs, and polybrominated bisphenol A compounds," Environmental Health Perspectives, vol. 109, no. 4, pp. 399-407, 2001.

[58] R. Recio-Vega, V. Velazco-Rodriguez, G. Ocampo-Gómez, S. Hernandez-Gonzalez, P. Ruiz-Flores, and F. Lopez-Marquez, "Serum levels of polychlorinated biphenyls in Mexican women and breast cancer risk," Journal of Applied Toxicology, vol. 31, no. 3, pp. 270-278, 2011.

[59] J. A. Rusiecki, T. R. Holford, S. H. Zahm, and T. Zheng, "Polychlorinated biphenyls and breast cancer risk by combined estrogen and progesterone receptor status," European Journal of Epidemiology, vol. 19, no. 8, pp. 793-801, 2004.
[60] F. Laden, N. Ishibe, S. E. Hankinson et al., "Polychlorinated biphenyls, cytochrome P450 1A1, and breast cancer risk in the Nurses' Health Study," Cancer Epidemiology Biomarkers and Prevention, vol. 11, no. 12, pp. 1560-1565, 2002.

[61] S. Pang, J. Q. Cao, B. H. Katz, C. L. Hayes, T. R. Sutter, and D. C. Spink, "Inductive and inhibitory effects of non-orthosubstituted polychlorinated biphenyls on estrogen metabolism and human cytochromes P450 1A1 and 1B1," Biochemical Pharmacology, vol. 58, no. 1, pp. 29-38, 1999.

[62] A. Ptak, G. Ludewig, A. Rak, W. Nadolna, M. Bochenek, and E. L. Gregoraszczuk, "Induction of cytochrome P450 1A1 in MCF7 human breast cancer cells by 4-chlorobiphenyl (PCB3) and the effects of its hydroxylated metabolites on cellular apoptosis," Environment International, vol. 36, no. 8, pp. 935-941, 2010.

[63] C. H. Lin, C. L. Huang, M. C. Chuang et al., "Protective role of estrogen receptor-alpha on lower chlorinated PCB congenerinduced DNA damage and repair in human tumoral breast cells," Toxicology Letters, vol. 188, no. 1, pp. 11-19, 2009.

[64] S. Radice, E. Chiesara, S. Fucile, and L. Marabini, "Different effects of PCB101, PCB118, PCB138 and PCB153 alone or mixed in MCF-7 breast cancer cells," Food and Chemical Toxicology, vol. 46, no. 7, pp. 2561-2567, 2008.

[65] A. Ptak, K. Mazur, and E. L. Gregoraszczuk, "Comparison of combinatory effects of PCBs $(118,138,153$ and 180) with $17 \beta$ estradiol on proliferation and apoptosis in MCF-7 breast cancer cells," Toxicology and Industrial Health, vol. 27, no. 4, pp. 315-321, 2011.

[66] S. Liu, S. Li, and Y. Du, "Polychlorinated biphenyls (PCBs) enhance metastatic properties of breast cancer cells by activating rho-associated kinase (ROCK)," PLoS ONE, vol. 5, no. 6, Article ID el1272, 2010.

[67] S. Y. Eum, Y. W. Lee, B. Hennig, and M. Toborek, "VEGF regulates PCB 104-mediated stimulation of permeability and transmigration of breast cancer cells in human microvascular endothelial cells," Experimental Cell Research, vol. 296, no. 2, pp. 231-244, 2004.

[68] J. L. Barber, M. J. Walsh, R. Hewitt, K. C. Jones, and F. L. Martin, "Low-dose treatment with polybrominated diphenyl ethers (PBDEs) induce altered characteristics in MCF-7 cells," Mutagenesis, vol. 21, no. 5, pp. 351-360, 2006.

[69] M. Mercado-Feliciano and R. M. Bigsby, "The polybrominated diphenyl ether mixture DE-71 ls. Mildly estrogenic," Environmental Health Perspectives, vol. 116, no. 5, pp. 605-611, 2008.

[70] Z. H. Li, X. Y. Liu, N. Wang et al., "Effects of decabrominated diphenyl ether (PBDE-209) in regulation of growth and apoptosis of breast, ovarian, and cervical cancer cells," Environmental Health Perspectives, vol. 120, pp. 541-546, 2012.

[71] P. Kwiecińska, A. Wróbel, and E. Ł. Gregoraszczuk, "Combinatory effects of PBDEs and 17 $\beta$-estradiol on MCF-7 cell proliferation and apoptosis," Pharmacological Reports, vol. 63, pp. 189-194, 2011.

[72] T. J. Murray, M. V. Maffini, A. A. Ucci, C. Sonnenschein, and A. M. Soto, "Induction of mammary gland ductal hyperplasias and carcinoma in situ following fetal bisphenol A exposure," Reproductive Toxicology, vol. 23, no. 3, pp. 383-390, 2007.

[73] M. Durando, L. Kass, J. Piva et al., "Prenatal bisphenol A exposure induces preneoplastic lesions in the mammary gland in wistar rats," Environmental Health Perspectives, vol. 115, no. 1, pp. 80-86, 2007.

[74] R. A. Keri, S. M. Ho, P. A. Hunt, K. E. Knudsen, A. M. Soto, and G. S. Prins, "An evaluation of evidence for the carcinogenic 
activity of bisphenol A," Reproductive Toxicology, vol. 24, no. 2, pp. 240-252, 2007.

[75] S. V. Fernandez and J. Russo, "Estrogen and Xenoestrogens in breast cancer," Toxicologic Pathology, vol. 38, no. 1, pp. 110-122, 2010.

[76] C. M. Olsen, E. T. M. Meussen-Elholm, M. Samuelsen, J. A. Holme, and J. K. Hongslo, "Effects of the environmental oestrogens bisphenol A, tetrachlorobisphenol A, tetrabromobisphenol A, 4-hydroxybiphenyl and 4,4'-dihydroxybiphenyl on oestrogen receptor binding, cell proliferation and regulation of oestrogen sensitive proteins in the human breast cancer cell line MCF7," Pharmacology and Toxicology, vol. 92, no. 4, pp. 180-188, 2003.

[77] A. Ricupito, G. Del Pozzo, N. Diano et al., "Effect of bisphenol A with or without enzyme treatment on the proliferation and viability of MCF-7 cells," Environment International, vol. 35, no. 1, pp. 21-26, 2009.

[78] P. Diel, S. Olff, S. Schmidt, and H. Michna, "Effects of the environmental estrogens bisphenol A, o, $\mathrm{p}^{\prime}$-DDT, p-tert-octylphenol and coumestrol on apoptosis induction, cell proliferation and the expression of estrogen sensitive molecular parameters in the human breast cancer cell line MCF-7," Journal of Steroid Biochemistry and Molecular Biology, vol. 80, no. 1, pp. 61-70, 2002.

[79] H. R. Lee, K. A. Hwang, M. A. Park, B. R. Yi, E. B. Jeung, and K. C. Choi, "Treatment with bisphenol A and methoxychlor results in the growth of human breast cancer cells and alteration of the expression of cell cycle-related genes, cyclin D1 and p21, via an estrogen receptor-dependent signaling pathway," International Journal of Molecular Medicine, vol. 29, pp. 883-890, 2012.

[80] V. Bencko, "Human exposure to endocrine disrupters: carcinogenic risk assessment," Folia Histochemica et Cytobiologica, vol. 39, no. 2, pp. 24-25, 2001.

[81] T. A. L. Brevini, S. B. Zaneto, and F. Cillo, "Effects of endocrine disruptors on developmental and reproductive functions," Current Drug Targets, vol. 5, no. 1, pp. 1-10, 2005.

[82] P. O. Darnerud and S. Risberg, "Tissue localisation of tetra- and pentabromodiphenyl ether congeners (BDE-47, -85 and -99) in perinatal and adult C57BL mice," Chemosphere, vol. 62, no. 3, pp. 485-493, 2006.

[83] C. E. Talsness, S. N. Kuriyama, A. Sterner-Kock et al., "In utero and lactational exposures to low doses of polybrominated diphenyl ether-47 alter the reproductive system and thyroid gland of female rat offspring," Environmental Health Perspectives, vol. 116, no. 3, pp. 308-314, 2008.

[84] C. A. Hilliard, M. J. Armstrong, C. I. Bradt, R. B. Hill, S. K. Greenwood, and S. M. Galloway, "Chromosome aberrations in vitro related to cytotoxicity of nonmutagenic chemicals and metabolic poisons," Environmental and Molecular Mutagenesis, vol. 31, pp. 316-326, 1998.

[85] S. M. Galloway, J. E. Miller, M. J. Armstrong, C. L. Bean, T. R. Skopek, and W. W. Nichols, "DNA synthesis inhibition as an indirect mechanism of chromosome aberrations: comparison of DNA-reactive and non-DNA-reactive clastogens," Mutation Research, vol. 400, no. 1-2, pp. 169-186, 1998.

[86] R. R. Newbold, W. N. Jefferson, and E. Padilla-Banks, "Longterm adverse effects of neonatal exposure to bisphenol $\mathrm{A}$ on the murine female reproductive tract," Reproductive Toxicology, vol. 24, no. 2, pp. 253-258, 2007.

[87] A. Ptak, A. Wróbel, and E. L. Gregoraszczuk, "Effect of bisphenol-A on the expression of selected genes involved in cell cycle and apoptosis in the OVCAR-3 cell line," Toxicology Letters, vol. 202, no. 1, pp. 30-35, 2011.
[88] K. A. Hwang, S. H. Park, B. R. Yi, and K. C. Choi, "Gene alterations of ovarian cancer cells expressing estrogen receptors by estrogen and bisphenol a using microarray analysis," Laboratory Animal Research, vol. 27, pp. 99-107, 2011.

[89] A. Ptak and E. L. Gregoraszczuk, "Bisphenol A induces leptin receptor expression, creating more binding sites for leptin, and activates the JAK/Stat, MAPK/ERK and PI3K/Akt signalling pathways in human ovarian cancer cell," Toxicology Letters, vol. 210, pp. 332-337, 2012. 


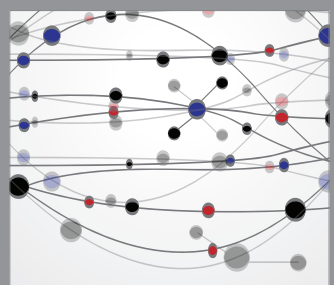

The Scientific World Journal
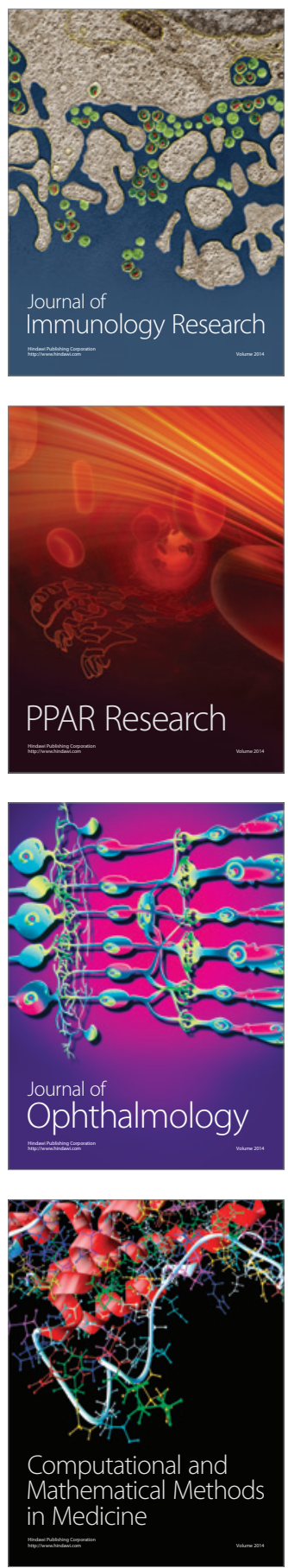

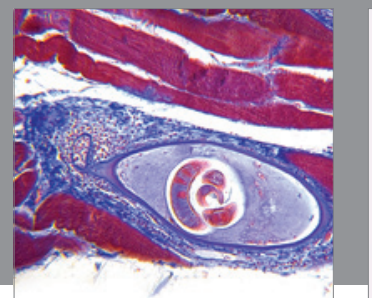

Gastroenterology

Research and Practice
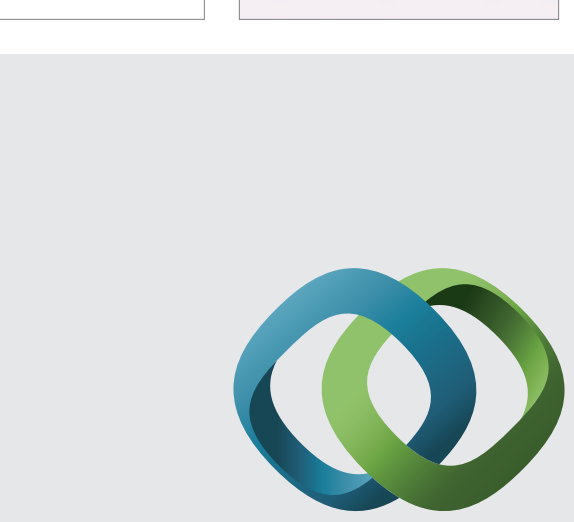

\section{Hindawi}

Submit your manuscripts at

http://www.hindawi.com
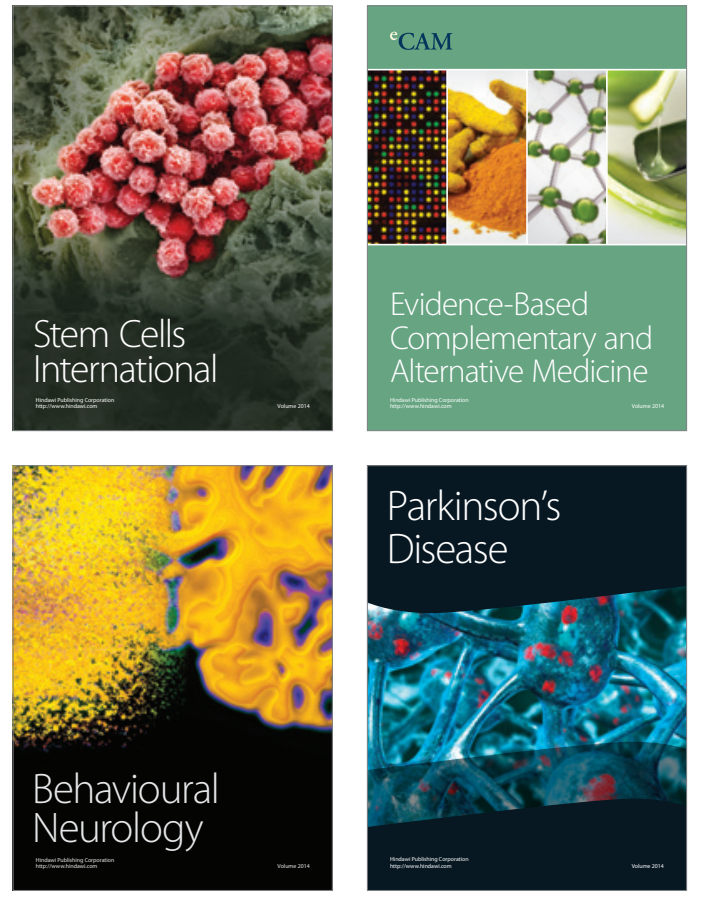
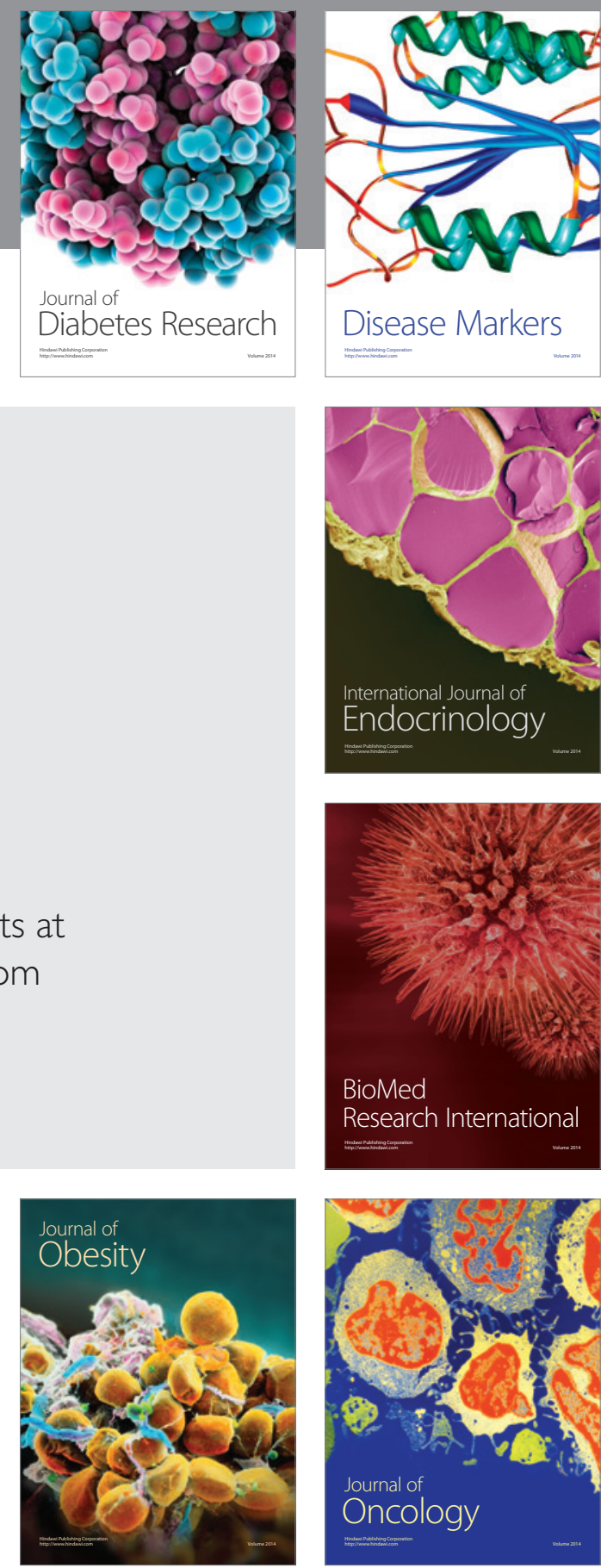

Disease Markers
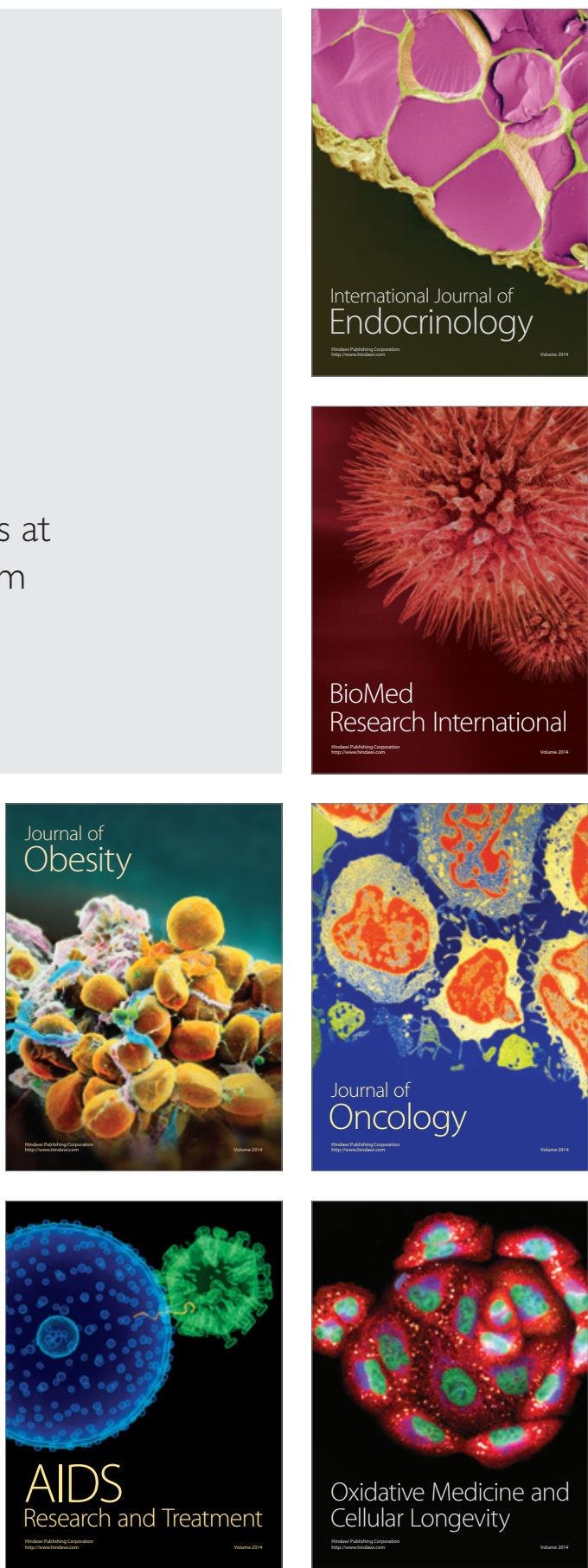